\title{
The Crystal Structure of Acetylcholine $\beta$-Resorcylate
}

\author{
BIRTHE JENSEN
}

Chemical Laboratory C, The Royal Danish School of Pharmacy, DK-2100 Copenhagen, Denmark

Acetylcholine $\beta$-resorcylate, $\mathrm{C}_{14} \mathrm{H}_{21} \mathrm{NO}_{6}$, crystallizes in space group $P 2_{1} / c$ with a unit cell having dimensions $a=14.562(6), b=14.109(4)$, $c=15.096(6) \AA$, and $\beta=106.90(3)^{\circ} . Z=8$. The structure was determined by direct methods from diffractometer collected three-dimensional $X$-ray data and refined by full-matrix leastsquares techniques to an $R$ index of 0.078 . Layers of $\beta$-resorcylate ions alternate with layers of acetylcholine ions. The $\beta$-resorcylate ions are linked together in infinite chains by strong hydrogen bonds while no hydrogen bonds involve the acetylcholine ions.

The crystal structure determination of acetylcholine $\beta$-resorcylate was taken up as part of conformational studies of choline derivatives in<smiles>CC(=O)OCC[N+](C)=Cc1cc(C(=O)[O-])c(O)cc1O</smiles>

the solid state. The crystal structures of a large number of salts of choline derivatives are known. Among these the carbamoylcholine salts ${ }^{1-2}$ seem to be exceptional, showing an apparently greater flexibility than found for most other choline derivatives. This is in agreement with the PCILO calculations of Pullman and Courière. ${ }^{3}$ However, it is noticed, that in all known crystal structures of carbamoylcholine salts the two possible hydrogen bonds $\mathrm{N}-\mathrm{H} \cdots \mathrm{X}$ are actually found, and the possibility is not precluded that the formation of these hydrogen bonds is of importance for the observed conformational changes. Among the salts of other choline derivatives, of which the crystal structures have been determined, only very fow have any possibility of formation of hydrogen bonds. It therefore seems to be of interest to examine salts of choline derivatives with hydroxy acids and other potential hydrogen bond donors, especially in view of the actions of acetylcholine in biological media.

\section{EXPERIMENTAL}

Acetylcholine $\beta$-resorcylate was prepared from an aqueous solution of acetylcholine chloride and excess of freshly precipitated silver salt of $\beta$-resorcylic acid. After stirring for $1 \mathrm{~h}$ the precipitate was filtered off, and the solution evaporated in vacuo. Colourless prisms of acetylcholine $\beta$-resorcylate were obtained by recrystallization from ethanol. The crystals used for the X-ray examination were grown by diffusion at room temperature of dimethoxymethane into a solution of the compound in ethanol containing $5 \%$ water.

Crystal data. Acetylcholine $\beta$-resorcylate, $\mathrm{C}_{14} \mathrm{H}_{21} \mathrm{NO}_{6}, \mathrm{M}=299.33$. M.p. $144.5-147^{\circ} \mathrm{C}$ (decomp.). Monoclinic, $a=14.562(6), b=14.109(4)$, $c=15.096(6) \AA . \beta=106.90^{\circ}, U=2967.6 \AA^{3} . D_{\mathrm{m}}=$ $1.33 \mathrm{~g} \mathrm{~cm}^{-3}, Z=8, D_{\mathrm{c}}=1.34 \mathrm{~g} \mathrm{~cm}^{-3}$. Linear absorption coefficient for X-rays $[\lambda(\operatorname{Mo} K \alpha)=$ $0.7107 \AA], \mu=1.1 \mathrm{~cm}^{-1} . F(000)=1280$. Systematically absent reflections: $h 0 l$ when $l$ is odd, $0 k 0$ when $k$ is odd: space group $P 2_{1} / c$.

The unit-cell parameters were refined by least-squares techniques from the diffractometer-measured $\theta$ angles observed for 33 reflections. The crystal density was measured by flotation in a mixture of chlorobenzene and bromobenzene. The melting point was determined on a Leitz hot stage microscope.

Data collection. Three-dimensional diffraction data were measured at room temperature (20$22^{\circ} \mathrm{C}$ ) on a Nonius three-circle automatic dif-

Acta Chem. Scand. B 29 (1975) No. 5 
Table 1. Atomic parameters with estimated standard deviations, referring to the last significant figure, in parenthesis. Positional parameters are $\times 10^{4}$. Thermal parameters are $\times 10^{2}$. The temperature factor is defined by

$\exp \left[-2 \pi^{2}\left(U_{11} h^{2} a^{* 2}+\cdots+2 U_{12} h k a^{*} b^{*}+\cdots \cdot\right)\right]$

\begin{tabular}{|c|c|c|c|c|c|c|c|c|c|}
\hline Atom & $x / a$ & $y / b$ & $z / c$ & $U_{11}$ & $U_{22}$ & $U_{33}$ & $U_{12}$ & $U_{13}$ & $U_{28}$ \\
\hline$C(11)$ & 2234(4) & $1723(4)$ & $0104(3)$ & $4.0(3)$ & $5.0(3)$ & $3.1(3)$ & $0.3(2)$ & $1.4(2)$ & $-0.2(2)$ \\
\hline$C(12)$ & $2197(4)$ & $2395(4)$ & $0775(4)$ & $4.1(3)$ & $4.9(3)$ & $3.9(3)$ & $-0.2(3)$ & $0.8(2)$ & $-0.5(3)$ \\
\hline $\mathrm{C}(13)$ & $2200(4)$ & $2100(4)$ & $1665(3)$ & $5.3(3)$ & $4.9(3)$ & $2.6(3)$ & $-0.4(3)$ & $1.1(2)$ & $-0.5(2)$ \\
\hline$C(14)$ & $2221(4)$ & $1155(4)$ & $1865(4)$ & $4.6(3)$ & $5.6(4)$ & $3.4(3)$ & $0.3(3)$ & $0.7(2)$ & $0.4(3)$ \\
\hline$C(15)$ & $2258(4)$ & $0477(4)$ & $1209(4)$ & $5.1(3)$ & $4.2(3)$ & $4.7(3)$ & $0.3(3)$ & $1.1(3)$ & $-0.4(3)$ \\
\hline$C(16)$ & $2262(4)$ & $0772(4)$ & $0334(4)$ & $4.7(3)$ & $5.6(4)$ & $3.7(3)$ & $0.2(3)$ & $1.2(3)$ & $-0.4(3)$ \\
\hline$C(17)$ & $2262(4)$ & $2037(5)$ & $-0836(4)$ & $4.4(3)$ & $6.5(4)$ & $3.9(3)$ & $0.3(3)$ & $1.0(3)$ & $-0.3(3)$ \\
\hline$O(171)$ & $2318(3)$ & $1436(3)$ & $-1417(3)$ & $8.9(3)$ & $7.3(3)$ & $4.4(2)$ & $0.0(3)$ & $3.0(2)$ & $-0.7(2)$ \\
\hline$O(172)$ & $2221(3)$ & $2933(3)$ & $-0990(3)$ & $8.9(3)$ & $6.5(3)$ & $4.4(2)$ & $0.1(2)$ & $3.1(2)$ & $0.9(2)$ \\
\hline$O(12)$ & $2183(3)$ & $3342(3)$ & 0604(3) & $8.5(3)$ & $4.7(2)$ & $4.8(2)$ & $-0.3(2)$ & $2.9(2)$ & $0.1(2)$ \\
\hline$O(14)$ & $2215(3)$ & $0856(3)$ & $2727(3)$ & $8.7(3)$ & $6.0(3)$ & $3.4(2)$ & $-0.1(2)$ & $1.9(2)$ & $1.1(2)$ \\
\hline$C(21)$ & $7143(4)$ & $3098(4)$ & $1060(3)$ & $4.0(3)$ & $4.8(3)$ & $2.9(3)$ & $-0.4(2)$ & $1.4(2)$ & $-0.4(2)$ \\
\hline $\mathrm{C}(22)$ & $7330(4)$ & $2476(4)$ & $0403(4)$ & $4.0(3)$ & $3.6(3)$ & $4.0(3)$ & $-0.2(2)$ & $1.6(2)$ & $-0.4(2)$ \\
\hline$C(23)$ & $7359(4)$ & $2827(4)$ & $-0456(4)$ & $5.1(3)$ & $4.8(3)$ & $3.7(3)$ & $0.2(3)$ & $2.0(3)$ & $-0.2(3)$ \\
\hline$C(24)$ & $7209(4)$ & $3780(4)$ & $-0652(4)$ & $5.0(3)$ & $4.8(3)$ & $3.1(3)$ & $-0.1(3)$ & $1.4(2)$ & $-0.1(3)$ \\
\hline$C(25)$ & $7016(4)$ & $4406(4)$ & $-0014(4)$ & $6.1(4)$ & $4.7(3)$ & $3.7(3)$ & $0.2(3)$ & $1.2(3)$ & $-0.2(3)$ \\
\hline$C(26)$ & $6992(4)$ & 4046(4) & $0830(4)$ & $4.9(3)$ & $5.0(3)$ & 3.7(3) & $0.0(3)$ & $1.2(3)$ & $-0.5(3)$ \\
\hline $\mathrm{C}(27)$ & $7145(4)$ & $2751(5)$ & $1994(4)$ & $4.6(3)$ & $6.2(4)$ & $3.2(3)$ & $-0.8(3)$ & $1.3(3)$ & $-0.4(3)$ \\
\hline$O(271)$ & $6932(4)$ & $\mathbf{3 3 0 2 ( 3 )}$ & $2543(3)$ & $10.1(4)$ & $7.1(3)$ & $4.0(2)$ & $1.0(3)$ & $3.6(2)$ & $0.1(2)$ \\
\hline$O(272)$ & $7388(3)$ & $1876(3)$ & $2177(3)$ & $9.2(3)$ & $5.1(3)$ & $4.4(2)$ & $0.1(2)$ & $3.0(2)$ & $0.6(2)$ \\
\hline$O(22)$ & 7484(3) & $1542(3)$ & $0586(3)$ & $8.7(3)$ & $3.8(2)$ & $4.8(2)$ & $0.4(2)$ & $2.7(2)$ & $0.4(2)$ \\
\hline$O(24)$ & $7232(3)$ & $4144(3)$ & $-1479(3)$ & $9.6(3)$ & $5.0(2)$ & $4.1(2)$ & $0.4(2)$ & $3.2(2)$ & $0.6(2)$ \\
\hline$C(31)$ & $4600(5)$ & $3500(5)$ & $-0424(5)$ & 7.4(5) & $8.5(5)$ & $5.2(4)$ & $0.2(4)$ & $2.3(3)$ & $-0.5(4)$ \\
\hline $\mathrm{C}(32)$ & $4637(4)$ & $2957(5)$ & $0436(5)$ & $4.8(4)$ & $6.6(5)$ & $5.7(4)$ & $0.5(3)$ & $1.7(3)$ & $-1.5(3)$ \\
\hline $\mathbf{O ( 3 3 )}$ & $4716(4)$ & $2108(4)$ & $0526(3)$ & $9.6(4)$ & $5.9(3)$ & $7.9(3)$ & $0.8(3)$ & 3.8(3) & $-1.5(3)$ \\
\hline $\mathrm{O}(\mathbf{3 4})$ & $4566(3)$ & 3532(3) & $1123(3)$ & $6.8(3)$ & $5.9(3)$ & $5.0(2)$ & $0.1(2)$ & $2.2(2)$ & $-0.9(2)$ \\
\hline $\mathbf{C}(\mathbf{3 5})$ & $4559(5)$ & $3070(4)$ & $1976(4)$ & $7.0(4)$ & $5.3(4)$ & $5.5(4)$ & $-0.2(3)$ & $2.5(3)$ & $-0.6(3)$ \\
\hline$C(36)$ & $4108(4)$ & $3741(4)$ & $2515(4)$ & $4.9(3)$ & $5.8(4)$ & $5.0(3)$ & $-0.6(3)$ & $1.6(3)$ & $-0.7(3)$ \\
\hline$N(37)$ & $4777(3)$ & $4470(3)$ & $3109(3)$ & $4.7(3)$ & $5.1(3)$ & $3.9(2)$ & $0.3(2)$ & $1.4(2)$ & $0.1(2)$ \\
\hline $\mathrm{C}(\mathbf{3 8})$ & $5193(5)$ & $5106(5)$ & $2524(5)$ & $8.5(5)$ & $6.1(4)$ & $5.0(4)$ & $-1.4(4)$ & $2.6(4)$ & $0.6(3)$ \\
\hline C(39) & $5581(5)$ & $4016(5)$ & $3842(4)$ & $5.7(4)$ & 7.4(4) & $4.1(3)$ & $0.6(3)$ & $0.7(3)$ & $0.8(3)$ \\
\hline$C(310)$ & $4177(5)$ & $5050(5)$ & $3571(5)$ & $6.8(4)$ & $7.1(5)$ & $6.1(4)$ & $1.2(4)$ & $2.4(3)$ & $-1.2(4)$ \\
\hline$C(41)$ & $9718(5)$ & $3575(6)$ & $5182(5)$ & $7.3(5)$ & $9.9(6)$ & $7.7(5)$ & $0.6(4)$ & 3.5(4) & $1.3(5)$ \\
\hline$C(42)$ & $9708(5)$ & $3090(6)$ & $4312(6)$ & $5.2(4)$ & $7.9(5)$ & $8.8(5)$ & $0.2(4)$ & $2.9(4)$ & $2.5(5)$ \\
\hline$O(43)$ & $9704(5)$ & $2249(5)$ & $4201(5)$ & $12.3(5)$ & $8.2(4)$ & $12.5(5)$ & $0.7(4)$ & $5.4(4)$ & $1.8(4)$ \\
\hline$O(44)$ & 9701(4) & $3707(4)$ & $3638(3)$ & $10.2(4)$ & $8.3(4)$ & $6.3(3)$ & $-2.4(3)$ & $2.1(3)$ & $1.1(3)$ \\
\hline$C(45)$ & $9687(8)$ & $3275(7)$ & $2744(6)$ & $17.1(10)$ & $8.9(6)$ & $6.7(5)$ & $-4.4(6)$ & $2.0(6)$ & $0.2(5)$ \\
\hline$C(46)$ & 9419(7) & $3919(7)$ & $2040(7)$ & $14.2(8)$ & $9.6(7)$ & $9.3(7)$ & $-3.4(6)$ & $3.4(6)$ & $-0.2(6)$ \\
\hline $\mathbf{N}(47)$ & $10107(4)$ & $4685(4)$ & $1885(4)$ & $5.7(3)$ & $6.3(3)$ & $6.0(3)$ & $0.4(3)$ & $2.6(3)$ & $0.1(3)$ \\
\hline$C(48)$ & $10426(6)$ & $5292(6)$ & $2712(6)$ & $11.3(7)$ & $7.6(5)$ & $7.7(5)$ & $-2.9(5)$ & $2.2(5)$ & $-1.2(4)$ \\
\hline$C(49)$ & $10915(6)$ & $4326(8)$ & $1580(6)$ & $8.1(6)$ & $19.1(10)$ & $9.6(7)$ & $5.8(6)$ & $4.4(5)$ & $2.6(7)$ \\
\hline$C(410)$ & $9454(6)$ & $5239(7)$ & $1101(6)$ & $8.6(6)$ & $14.1(8)$ & $7.0(5)$ & $5.0(6)$ & $1.6(4)$ & $1.7(5)$ \\
\hline
\end{tabular}

fractometer using graphite monochromated MoK$\alpha$ radiation. The $\omega$ scan technique with a scan speed of $1.2^{\circ} \mathrm{min}^{-1}$ was employed, and the scan angle was $1.2^{\circ}$. Background counts were taken for half the scanning time at each of the scan range limits. One standard reflection was measured after each 25 reflections. All the data were measured from a single crystal of irregular shape. The approximate dimensions were $0.20 \times$ $0.36 \times 0.48 \mathrm{~mm}$. The crystal was mounted with [001] along the $\phi$-axis of the goniostat. Out of the 5435 reflections measured in the range $2.5^{\circ} \leq \theta \leq 25^{\circ}, 2509$ had $I_{\text {net }} \geqq 2.5 \sigma(I)$, where $\sigma(I)$ is the standard deviation from counting 
statistics. These were regarded as observed reflections. Lorentz and polarization corrections were applied, but no absorption corrections were made owing to the low absorption coefficient.

Structure determination and refinement. The structure was solved by direct methods in a straight forward way using the programs of the X-RAY system." In an $E$-map based on 299 $E(h k l)$ 's with $|E(h k l)| \geq 1.7$ the 29 highest peaks were found in positions corresponding to the heavier atoms of the two $\beta$-resorcylate ions and to seven atoms $[C(31)-N(37)]$ of one of the acetylcholine ions. Seven more of the higher peaks were found at correct atomic positions [corresponding to $\mathrm{C}(38)-\mathrm{C}(310)$ and $\mathrm{C}(41)-$ $O(44)]$. From an electron density map calculated using the phases from the contributions of the above mentioned 29 atoms the positions of the remaining 13 atoms in the asymmetric unit could be deduced. Individual atomic parameters of all 42 carbon, nitrogen, and oxygen atoms were refined using the full-matrix leastsquares method. Owing to the great number of variables the refinements were performed in a few big blocks. A three-dimensional difference synthesis calculated at the stage of convergence of the refinement using individual isotropic temperature factors $(R \sim 0.14)$ showed maxima at the calculated positions for 19 of the 42 hydrogen atoms, namely the hydrogen atoms bonded to the benzene rings and 13 of the 16 hydrogen atoms of one of the acetylcholine ions, III. The 19 hydrogen atoms were introduced in the refinement as a fixed contribution in the calculated positions and with arbitrary temperature factors. After refinement of the heavier atoms using individual anisotropic temperature factors a difference synthesis based only on reflections for which $\sin \theta / \lambda \leq 0.35$ was examined, but from this only the positions of the four $\mathrm{OH}$-hydrogen atoms could further be postulated. Nevertheless all 42 hydrogen atoms were now introduced as a fixed contribution in the refinement, in an attempt to reduce the very strong "thermal motion" observed ( $c f$. Table 1). The three hydrogen atoms of each of

Table 2. Atomic parameters used for the hydrogen atoms. Positional parameters are $\times 10^{4}$. Thermal parameters are $\times 10^{2}$.

\begin{tabular}{|c|c|c|c|c|c|c|c|c|c|c|c|}
\hline Atom & $x / a$ & $y / b$ & $z / c$ & U & P.P. & Atom & $x / a$ & $y / b$ & $z / c$ & $\mathbf{U}$ & P.P. \\
\hline $\begin{array}{l}H(13) \\
H(15) \\
H(16) \\
H(12) \\
H(14)\end{array}$ & $\begin{array}{l}2177 \\
2285 \\
2269 \\
2200 \\
2200\end{array}$ & $\begin{array}{r}2577 \\
-0214 \\
0284 \\
3450 \\
1370\end{array}$ & $\begin{array}{r}2147 \\
1362 \\
-0141 \\
0000 \\
3200\end{array}$ & $\begin{array}{l}5.1 \\
5.1 \\
5.1 \\
7.6 \\
7.6\end{array}$ & & $\begin{array}{l}\mathbf{H}(391) \\
\mathbf{H}(392) \\
\mathbf{H}(393) \\
\mathbf{H}(3101) \\
\mathbf{H}(3102) \\
\mathbf{H}(3103)\end{array}$ & $\begin{array}{l}5304 \\
5962 \\
6015 \\
3659 \\
3916 \\
4628\end{array}$ & $\begin{array}{l}3626 \\
3625 \\
4512 \\
5365 \\
4624 \\
5524\end{array}$ & $\begin{array}{l}4244 \\
\mathbf{3 5 3 3} \\
\mathbf{4 2 3 4} \\
\mathbf{3 0 9 5} \\
\mathbf{3 9 6 3} \\
\mathbf{3 9 6 4}\end{array}$ & $\begin{array}{l}7.6 \\
7.6 \\
7.6 \\
7.6 \\
7.6 \\
7.6\end{array}$ & \\
\hline $\begin{array}{l}H(23) \\
H(25) \\
H(26) \\
H(22) \\
H(24)\end{array}$ & $\begin{array}{l}\mathbf{7 5 0 7} \\
\mathbf{6 8 9 8} \\
\mathbf{6 8 3 6} \\
\mathbf{7 3 5 0} \\
\mathbf{7 3 5 0}\end{array}$ & $\begin{array}{l}2384 \\
5094 \\
4490 \\
1430 \\
3820\end{array}$ & $\begin{array}{r}-0920 \\
-0160 \\
1281 \\
1240 \\
-1960\end{array}$ & $\begin{array}{l}5.1 \\
5.1 \\
5.1 \\
7.6 \\
7.6\end{array}$ & & $\begin{array}{l}H(4113) \\
H(4123) \\
H(4133) \\
H(4114) \\
H(4124)\end{array}$ & $\begin{array}{r}9138 \\
10309 \\
9698 \\
10303 \\
9131\end{array}$ & $\begin{array}{l}3333 \\
3357 \\
4282 \\
3978 \\
\mathbf{3 9 9 4}\end{array}$ & $\begin{array}{l}\mathbf{5 3 3 9} \\
\mathbf{5 6 4 4} \\
\mathbf{5 2 5 6} \\
\mathbf{5 3 8 0} \\
\mathbf{5 0 5 6}\end{array}$ & $\begin{array}{l}10.1 \\
10.1 \\
10.1 \\
10.1 \\
10.1\end{array}$ & $\begin{array}{l}0.5 \\
0.5 \\
0.5 \\
0.5 \\
0.5\end{array}$ \\
\hline $\begin{array}{l}\mathbf{H}(3113) \\
H(3123) \\
H(3133) \\
H(3114) \\
H(3124) \\
H(3134) \\
H(351) \\
H(352) \\
H(361) \\
H(362) \\
H(381) \\
H(382) \\
H(383)\end{array}$ & $\begin{array}{l}5182 \\
4014 \\
4522 \\
3957 \\
5123 \\
4630 \\
4161 \\
5222 \\
3589 \\
3839 \\
5576 \\
4672 \\
5637\end{array}$ & $\begin{array}{l}3340 \\
3242 \\
4211 \\
3854 \\
3975 \\
3086 \\
2484 \\
2912 \\
4094 \\
3356 \\
4707 \\
5437 \\
\mathbf{5 5 8 7}\end{array}$ & $\begin{array}{r}-0595 \\
-0913 \\
-0511 \\
-0630 \\
-0300 \\
-0952 \\
1836 \\
2357 \\
2058 \\
2928 \\
2200 \\
2051 \\
2916\end{array}$ & $\begin{array}{l}\mathbf{7 . 6} \\
\mathbf{7 . 6} \\
\mathbf{7 . 6} \\
\mathbf{7 . 6} \\
\mathbf{7 . 6} \\
\mathbf{7 . 6} \\
\mathbf{7 . 6} \\
\mathbf{7 . 6} \\
\mathbf{7 . 6} \\
\mathbf{7 . 6} \\
\mathbf{7 . 6} \\
\mathbf{7 . 6} \\
\mathbf{7 . 6}\end{array}$ & $\begin{array}{l}0.5 \\
0.5 \\
0.5 \\
0.5 \\
0.5 \\
0.5\end{array}$ & $\begin{array}{l}\mathbf{H}(4134) \\
\mathbf{H}(451) \\
\mathbf{H}(452) \\
\mathbf{H}(461) \\
\mathbf{H}(462) \\
\mathbf{H}(481) \\
\mathbf{H}(482) \\
\mathbf{H}(483) \\
\mathbf{H}(491) \\
\mathbf{H}(492) \\
\mathbf{H}(493) \\
\mathbf{H}(4101) \\
\mathbf{H}(4102) \\
\mathbf{H}(4103)\end{array}$ & $\begin{array}{r}9707 \\
10420 \\
9334 \\
9152 \\
8807 \\
9860 \\
10731 \\
10905 \\
11235 \\
10615 \\
11376 \\
9209 \\
8911 \\
9938\end{array}$ & $\begin{array}{l}\mathbf{3 1 2 3} \\
\mathbf{3 0 7 5} \\
\mathbf{2 6 6 7} \\
\mathbf{3 5 8 2} \\
\mathbf{4 2 9 3} \\
\mathbf{5 6 3 6} \\
\mathbf{4 8 9 4} \\
\mathbf{5 7 8 2} \\
\mathbf{3 7 7 0} \\
\mathbf{3 9 3 7} \\
\mathbf{4 7 3 5} \\
\mathbf{4 8 6 2} \\
\mathbf{5 5 4 6} \\
\mathbf{5 7 3 4}\end{array}$ & $\begin{array}{l}5680 \\
2821 \\
2658 \\
1391 \\
2086 \\
2794 \\
3247 \\
2629 \\
2032 \\
0954 \\
1498 \\
0524 \\
1268 \\
1030\end{array}$ & $\begin{array}{l}10.1 \\
10.1 \\
10.1 \\
10.1 \\
10.1 \\
10.1 \\
10.1 \\
10.1 \\
10.1 \\
10.1 \\
10.1 \\
10.1 \\
10.1 \\
10.1\end{array}$ & 0.5 \\
\hline
\end{tabular}

Acta Chem. Scand. B 29 (1975) No. 5 
Table 3. Least squares planes. The equations of the planes are in direct (unit cell) space. Distances (A) to atoms defining the plane are marked with an asterisk.

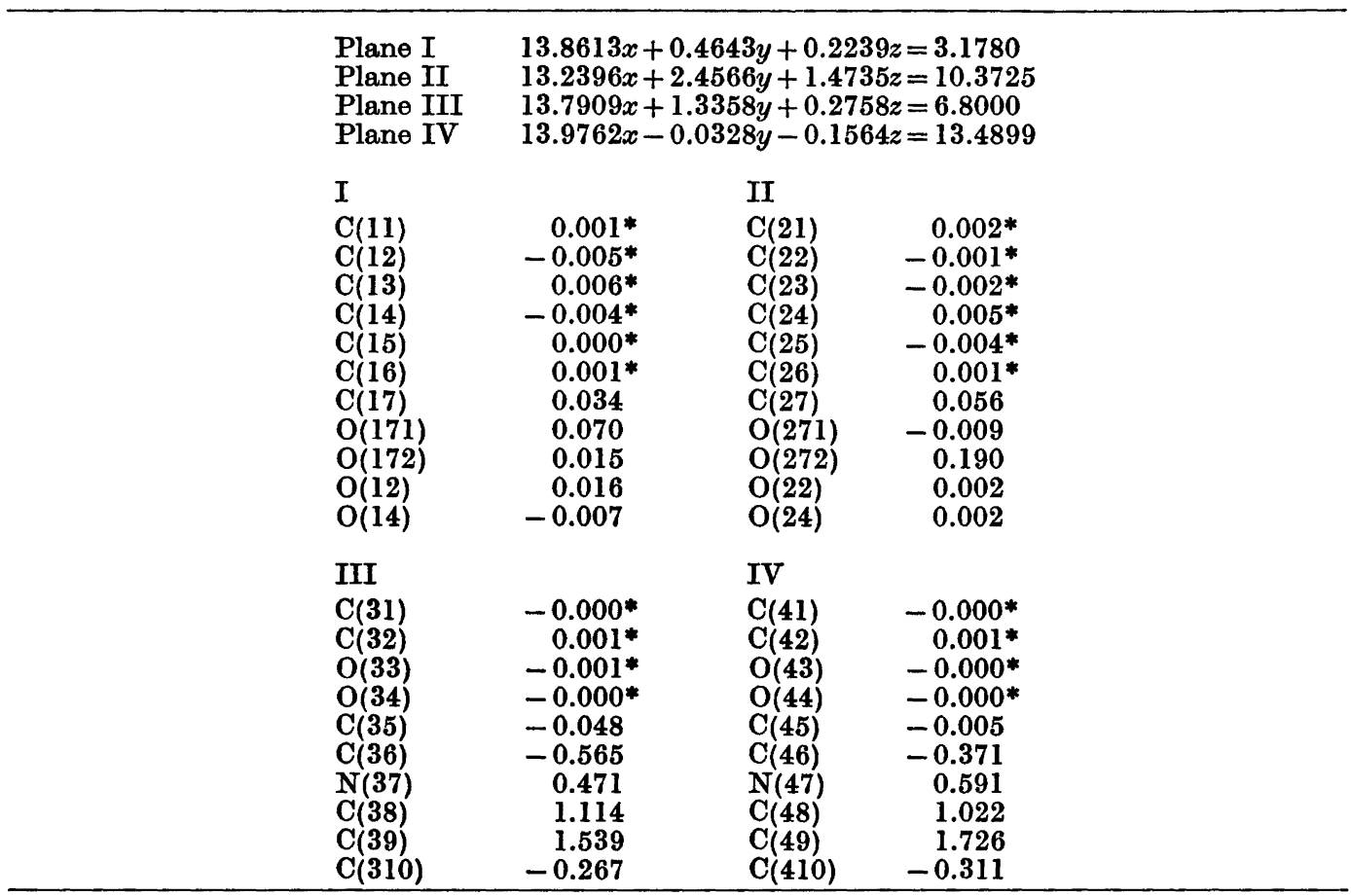

the two acetyl groups were introduced as two times six atoms with occupancy-factor 0.5 . On convergence of the refinement using anisotropic temperature factors the $R$-value was 0.078 . The quantity minimized was $\sum w\left(\left|F_{\mathrm{o}}\right|-\left|F_{\mathrm{c}}\right|\right)^{2}$, where weights were taken as a unity. A weight analysis showed this not to be too unsatisfactory and in view of the limited amount of data and the expence in computer time further refinement was judged not to be justified. In all calculations the contribution from unobserved reflections were included in the refinement, when $\left|F_{c}\right| \geq$ $\left|F_{\mathrm{o}}\right|$. All the atoms were treated as uncharged, and the form factors were taken from Interna. tional Tables for X-Ray Crystallography. ${ }^{5}$ The calculations were performed on a GIER com. puter and an IBM $360 / 75$ computer using INDIFF, a local version of The N.R.C. $2 A$ Picker Data Reduction Program," The X-Ray System," and ORTEP. ${ }^{\circ}$

The observed and calculated structure factor data are available from the author upon request.

The final atomic parameters of carbon, nitrogen and oxygen atoms are listed in Table 1. In
Table 2 the parameters used for the hydrogen atoms are given. Bond lengths and angles are shown in Fig. 1. The parameters of a number of planes calculated through parts of the ions are given in Table 3.

\section{RESULTS AND DISCUSSION}

The structure is built up of alternating negatively and positively charged puckered layers roughly parallel to $(100)$ and with an interlayer distance of approximately $x / 4, c f$. Fig. 2. Layers consisting of both of the crystallographically independent $\beta$-resorcylate ions $I$ and II are found about $x \sim 1 / 4$ and $x \sim 3 / 4$. A layer consisting of acetylcholine ions III only is found about $x \sim \frac{1}{2}$, and a layer of acetylcholine ions IV is situated about $x \sim 1.0$. The layers are held together by a great number of relatively weak interionic contacts. The resorcylate ions within each layer are linked together in infinite chains in the $c$ direction by strong hydrogen bonds $\mathrm{O}(\mathrm{x} 4)-\mathrm{H} \cdots \mathrm{O}(\mathrm{x} 72)$. Chains consisting of $\beta$ resorcylate ions I alternative with chains con- 


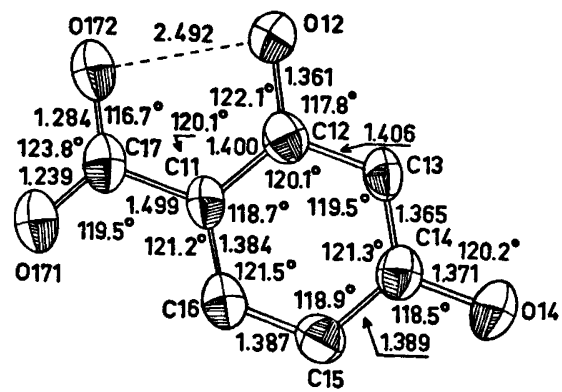

I

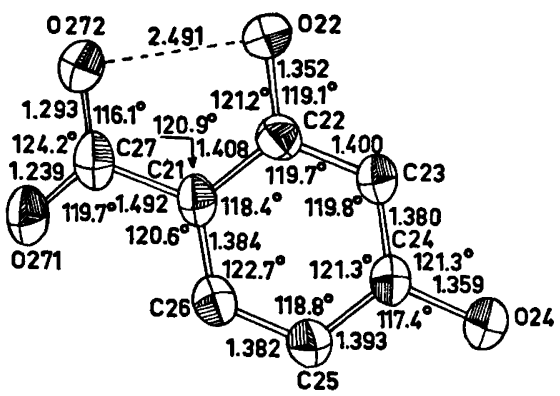

II

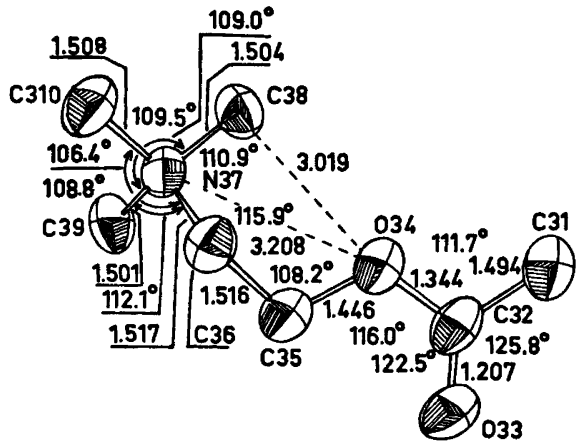

III

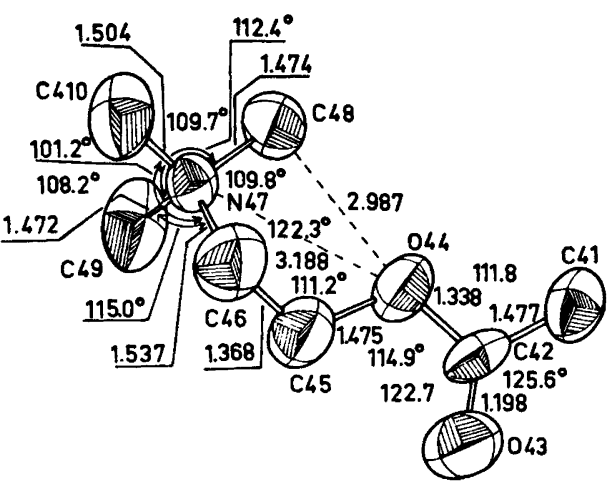

IV

Fig. 1. Numbering system, bond distances and bond angles of $\beta$-resorcylate ion $I, \beta$-resorcylate ion II, acetylcholine ion III, and acetylcholine ion IV. All ions are viewed along the $a^{*}$-axis. The intraionic hydrogen bonds of the $\beta$-resorcylate ions are indicated, and so are the distances $\mathrm{O}(\mathrm{x} 4) \cdots \mathrm{N}(\mathrm{x} 7)$ and $\mathrm{O}(\mathrm{x} 4) \cdots \mathrm{C}(\mathrm{x} 8)$ of the acetylcholine ions. The estimated standard deviations in bonds and angles are $0.008 \AA$ and $0.5^{\circ}$, respectively, for dimensions of the $\beta$-resorcylate ions, while the corresponding figures for dimensions of the acetylcholine ions are in the range $0.008-0.013 \AA$ and $0.4-0.8^{\circ}$, respectively.

sisting of $\beta$-resorcylate ions II. The $\mathrm{O}(x 4) \cdots$ $\mathrm{O}(\mathrm{x} 72)$ distance is $2.580 \AA$ when $\mathrm{x}=1$, and $2.550 \AA$ when $x=2$. No close contacts are found between the chains. The angle between (100) and the ring plane of $\beta$-resorcylate ion I is $2.1^{\circ}$, while the corresponding angle for $\beta$ resorcylate ion $\mathrm{II}$ is $11.5^{\circ}$. The angle between the ring planes I and II is $9.5^{\circ}$.

Within the layer consisting of acetylcholine ions III only very few contacts between the ions are observed, $c f$. Fig. 3a. The angle between the best plane through the atoms $\mathrm{C}(31), \mathrm{C}(32)$, $O(33)$ and $O(34)$ and the ring plane of resorcylate ion $I$ is $3.6^{\circ}$, and the corresponding angle to the ring plane of resorcylate ion II is $6.5^{\circ}$. The five atoms $\mathrm{C}(31)$ to $\mathrm{C}(35)$ are squeezed in between the resorcylate ions $I_{(x, y, z)}$ and $\mathrm{II}_{(x, y, z)}$. The distances of the five atoms to the planes of the two rings are in the range 3.3 to $3.5 \AA$, the shorter interatomic distances being of this magnitude too. A number of rather weak contacts are seen between the cationic head of the acetylcholine ion III and atoms, mostly oxygen atoms, of resorcylate ions in the two adjacent layers, $c f$. Fig. 3a.

The situation within the layer consisting of acetylcholine ions IV is very similar to that described for the layer of acetylcholine ions III. Only few contacts between the acetylcholine ions are found, $c f$. Fig. $3 \mathrm{~b}$. The angle between

Acta Chem. Scand. B 29 (1975) No. 5 

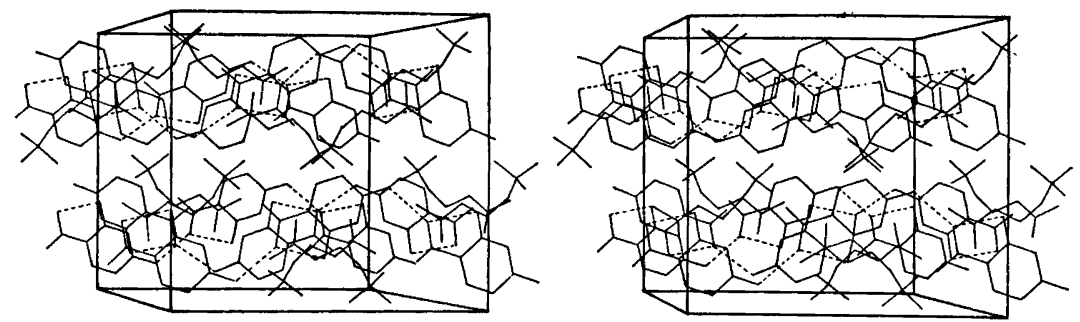

Fig. 2. Stereo diagram illustrating the packing. The $b$-axis is $\uparrow$, the $c$-axis is $\rightarrow$, and $a^{*}$ is pointing into the paper. Hydrogen bonds are drawn with broken lines.

(a)

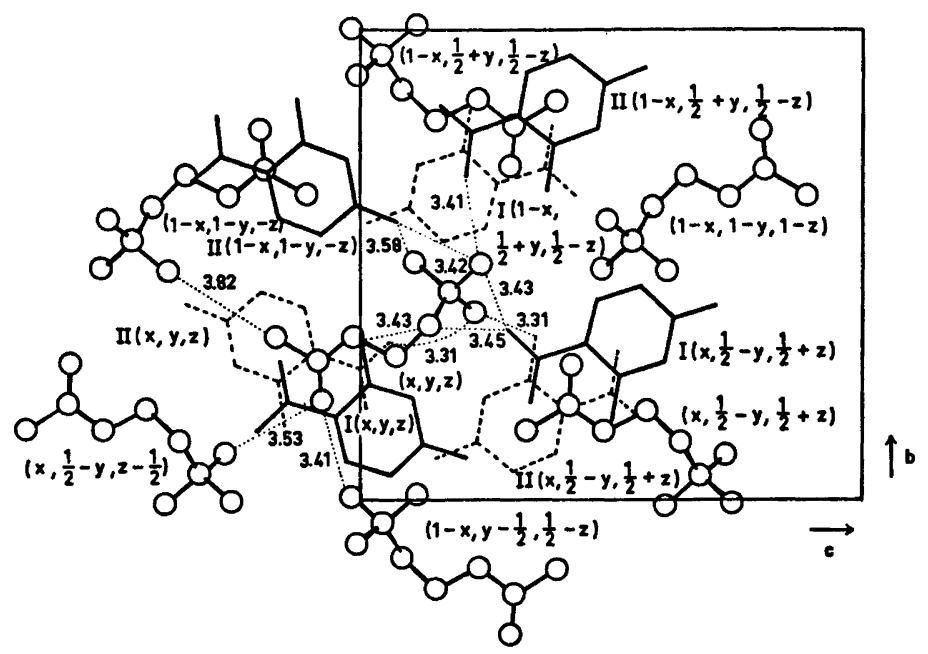

(b)

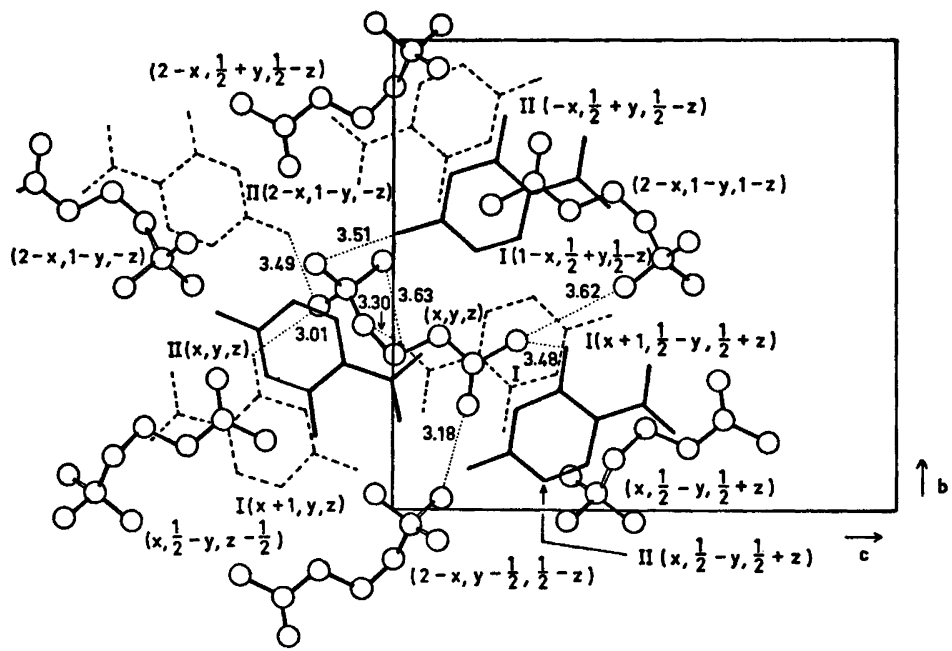

Fig. 3. Projection along $a^{*}$ of (a) the packing around acetylcholine-ion III and (b) the packing around acetylcholine-ion IV. 
the best plane through the atoms $\mathrm{C}(41), \mathrm{C}(42)$, $O(43)$, and $O(44)$ and the ring plane of resorcylate ion $I_{(x+1,1-y, z+z)}$ is $2.3^{\circ}$. The distances of the five atoms $C(41)$ to $C(45)$ to the plane of the above mentioned adjacent ring are all $\geq 3.5 \AA$. No resorcylate ion is found directly on top of the atoms of the ester group of acetylcholine ion IV. A number of contacts between the cationic head and resorcylate ions in the adjacent layers are observed. One of them, $C(49) \cdots$ $\mathrm{O}(14)_{(x+1, y, z)}$ is remarkably short, 3.01 $\AA$. The shortest contacts to $C(45)$ are $C(45) \cdots C(27)_{(x, y, 8)}$ $3.62 \AA$, and $\mathrm{C}(45) \cdots \mathrm{O}(171)_{\left(x+1, \frac{1}{2}-y, z+z\right)}, 3.69 \AA$.

The $\beta$-resorcylate ions. As visualized in Fig. 1 the dimensions of the two resorcylate ions I and II are very similar, and no significant differences between corresponding figures are found. As in the crystal structure of salicylic acid ${ }^{\circ}$ and of nicotinyl salicylate ${ }^{10}$ there is a strong hydrogen bond between the ortho-hydroxyl and a carboxylate oxygen atom. The distance $\mathrm{O}(\mathrm{x} 2) \cdots$ $\mathrm{O}(\mathrm{x} 72)$ is $2.49 \AA$. The corresponding distances in salicylic acid and in nicotinyl salicylate are 2.620 and $2.544 \AA$, respectively. The carbon - oxygen distances $\mathrm{C}(\mathrm{x} 7)-\mathrm{O}(\mathrm{x} 71)$ and $\mathrm{C}(\mathrm{x} 7)-\mathrm{O}(\mathrm{x} 72)$, 1.239 and $1.284 \AA$ for $x=1$, and 1.239 and $1.293 \AA$ for $x=2$, are significantly different. This difference is associated to the fact that $O(x 72)$ is acceptor for two strong hydrogen bonds, while no hydrogen bond involve $O(x 71)$. The distance $\mathrm{C}(\mathrm{x} 2)-\mathrm{O}(\mathrm{x} 2), 1.361 \AA$ and $1.352 \AA$ for the ions I and II, respectively, is of the same magnitude as the corresponding bond (1.358 $\AA$ ) in salicylic acid, and it thus seems doubtful whether the shortening of the corresponding bond (1.318 $\AA$ ) observed in the salicylate ion ${ }^{10}$ can be ascribed to an effect of the strength of the intraionic hydrogen bond. The carboxylate group is out of the plane of the benzene ring by 2 and $6^{\circ}$ for resorcylate ion I and II, respectively. These figures do not describe a torsion around the bond $\mathrm{C}(\mathrm{x} 1)-\mathrm{C}(\mathrm{x} 7)$, cf. Table 3 .

The acetylcholine ions. Rather pronounced differences are observed between the dimensions of the two crystallographically independent acetylcholine ions III and IV, $c f$. Fig. 1. Due to the extremely large "thermal motion" of acetylcholine ion IV these differences can, however, not be interpreted as significant differences in real bond lengths and angles. The bond lengths and angles of acetylcholine ion III are not significantly different from those found by
Table 4. Torsion angles $\left({ }^{\circ}\right)$ of the acetylcholineions III and IV.

\begin{tabular}{lrr}
\hline & III & \multicolumn{1}{c}{ IV } \\
& $x=3$ & \multicolumn{1}{c}{$x=4$} \\
\hline$C(x 1)-C(x 2)-O(x 4)-C(x 5)$ & \pm 178 & 180 \\
$C(x 2)-O(x 4)-C(x 5)-C(x 6)$ & \pm 159 & \pm 163 \\
$O(x 4)-C(x 5)-C(x 6)-N(x 7)$ & \pm 84 & \pm 77 \\
$C(x 5)-C(x 6)-N(x 7)-C(x 8)$ & \pm 61 & \pm 60 \\
\hline
\end{tabular}

Herdklotz and Sass ${ }^{11}$ in the crystal structure of acetylcholine chloride. The conformations of both of the acetylcholine ions are approximately the same and equal to that found in crystals of acetylcholine chloride, while differences from the conformation found by Canepa, Pauling and Sörum ${ }^{12}$ are observed. The pertinent torsion angles are listed in Table 4. The distances $\mathrm{O}(\mathrm{x} 4) \cdots \mathrm{N}(\mathrm{x} 7)$ and $\mathrm{O}(\mathrm{x} 4) \cdots \mathrm{C}(\mathrm{x} 8)$ are 3.21 and $3.02 \AA$ when $x=3$ and 3.19 and $2.99 \AA$ when $x=4$.

\section{REFERENCES}

1. Barrans, Y. Thèse, L'Université de Bordeaux, 1971.

2. Jensen, B. Abstract (Section $\mathrm{B}_{4}$ ) to First European Crystallographic Meeting, Bordeaux 1973.

3. Pullman, B. and Courrière, P. Theor. Chim. Acta 31 (1973) 19.

4. Stewart, J. M., Kruger, G. J., Amman, H. L., Dickinson, C. and Hall, S. R. X-Ray 72 Crystal Structure Calculation System, Computer Science Center, University of Maryland, June 1972.

5. International Tables for X-Ray Crystallography, Kynoch Press, Birmingham 1962, Vol. III.

6. Sørensen, A. M. INDIF F', An Algol Nonius Three-Circle Diffractometer Input Data Program, Chemical Laboratory C, The Royal Danish School of Pharmacy, DK-2100 Copenhagen 1968.

7. Ahmed, F. R. N. R. C. Crystallographic Program System, National Research Council Ottowa, Canada 1968.

8. Johnson, C. K. ORTEP: A Fortran Thermal Ellipsoid Plot Program for Crystal Structure Illustrations, Oak Ridge National Laboratory, Oak Ridge 1965.

9. Sundaralingam, M. and Jensen, L. H. Acta Crystallogr. 18 (1965) 1053.

10. Kim, H. S. and Jeffrey, G. A. Acta Crystallogr. $B 27$ (1971) 1123 .

11. Herdklotz, J. K. and Sass, R. L. Biochem. Biophys. Res. Commun. 40 (1970) 583.

12. Canepa, F. G., Pauling, $P$. and Sörum, H. Nature (London) 210 (1966) 907.

Received November 28, 1974.

Acta Chem. Scand. B 29 (1975) No. 5 